\begin{tabular}{|c|c|}
\hline Title & $\begin{array}{l}\text { Photo- and Thermal Interconversion of Multiconfigurational Strained Hydrocarbons Exhibiting Completely Switchable } \\
\text { Oxidation to Stable Dicationic Dyes }\end{array}$ \\
\hline Author(s) & Ishigaki, Y usuke; Hay ashi, Y uki; Suzuki, T akanori \\
\hline Citation & $\begin{array}{l}\text { Journal of the A merican Chemical Society, 141(45), 18293-18300 } \\
\text { https://doi.org/10.1021/Jacs.9b09646 }\end{array}$ \\
\hline Issue Date & 2019-11-13 \\
\hline Doc URL & http:/hdl.handle.net/2115/79593 \\
\hline Rights & $\begin{array}{l}\text { This document is the A ccepted Manuscript version of a Published Work that appeared in final form in Journal of the } \\
\text { A merican Chemical Society, copyright c A merican Chemical Society after peer review and technical editing by the } \\
\text { publisher. To access the final edited and published work see https:/pubs.acs.org/doi/abs/10.1021/jacs.9b09646. }\end{array}$ \\
\hline Tyре & article \\
\hline File Information & Ishigaki et al., J. A m. Chem. Soc. 2019, 141, 45, 18293-18300.pdf \\
\hline
\end{tabular}

Instructions for use 


\title{
Photo- and thermal interconversion of multi-configurational strained hydrocarbons exhibiting completely switchable oxidation to stable di- cationic dyes
}

\author{
Yusuke Ishigaki,* Yuki Hayashi, and Takanori Suzuki* \\ Department of Chemistry, Faculty of Science, Hokkaido University, Sapporo 060-0810, Japan \\ KEYWORDS: overcrowded ethylene, strained hydrocarbon, electrochromism, isomerization, selective oxidation
}

\begin{abstract}
Highly strained hydrocarbons with two di-/tri-benzocycloheptatriene units were designed as electrochromic overcrowded ethylenes that undergo reversible interconversion with stable dicationic dyes. Due to severe steric repulsion, two configurational isomers (anti,anti-folded and syn,anti-folded forms) were isolated as stable entities. Photo- and thermal interconversion of these isomers proceeded cleanly: one-way photoisomerization occurred from anti,anti- to syn,anti-form and one-way thermal isomerization was observed from syn,anti- to anti,anti-form. Even though both isomers undergo twoelectron oxidation into the same twisted dications, quite different oxidation potentials enable completely selective oxidation of syn,anti-isomers. Thus, the present multi-configurational strained hydrocarbons are capable of switching of activation/deactivation of their electrochromic properties by light/heat.
\end{abstract}

\section{- INTRODUCTION}

Extended $\pi$-conjugated molecules have been widely investigated for their unique physical properties that can be modified by proper molecular design. In particular, much attention has been focused on sterically congested and/or curved polycyclic aromatic hydrocarbons (PAHs) ${ }^{1-14}$ as well as cyclic $\pi$-conjugated molecules like cycloparaphenylenes ${ }^{15-21}$ and carbon nanobelts. ${ }^{22-24}$ These highly strained molecules are potential candidates with special characteristic features that are not found in normal compounds. Within such compounds, curved structures for PAHs are efficiently induced by incorporating mediumsized rings, such as seven-membered rings, which impart molecular strain and distortion. $3,4,7,8,10,11,13$

For example, we recently reported that highly strained hydrocarbons could be generated by connecting two dibenzocycloheptatriene units with a C-C bond, in which a sevenmembered ring is a key structure to induce severe strain to give a hyper covalent bond with a $\mathrm{C}$-C single bond length beyond $1.8 \AA .^{25}$ Such an elongated bond can be cleaved upon two-electron oxidation to give the corresponding stable dication [dynamic redox (dyrex) behavior] to exhibit electrochromic behavior. ${ }^{26}$ In other types of cycloheptatriene derivatives, multi conformations can be observed and a mechanism of their interconversion has been investigated. ${ }^{27-29}$

When the dibenzocycloheptatriene moieties are connected by a double bond, the $\mathrm{C}=\mathrm{C}$ unit cannot adopt a planar geometry. Deviation from standard planarity happens with an energy loss of $\pi$-conjugation to give strained molecules as in other overcrowded ethylenes (OCEs), ${ }^{30-35}$ in which the $\mathrm{C}=\mathrm{C}$ double bond is surrounded by bulky substituents. Since OCEs can often adopt multiple forms such as folded and/or twisted conformer(s), many OCEs exhibit photo- and thermochromic behavior upon exposure to external stimuli such as light and heat. We envisaged that advanced electrochromic OCEs could be realized, which could be activated/deactivated by light/heat by incorporating characteristic photo/thermal interconversion as a switching mechanism.

Several dibenzocycloheptatriene-based OCEs that include tetrabenzoheptafulvalene (TBHF) ${ }^{36}$ have been reported. The parent TBHF exhibits photo- and thermal isomerization between their anti- and syn-folded isomers because flipping of a seven-membered ring is hampered by steric hindrance in the overcrowded fjord region around the central $\mathrm{C}=\mathrm{C}$ double bond (Scheme 1 ). ${ }^{37-40}$. This observation can also be found in other types of TBHFs, as reported by Miao and co-workers. ${ }^{41}$ The formation of a dication was

Scheme 1. Molecular design for $\mathbf{1}$ and 2.

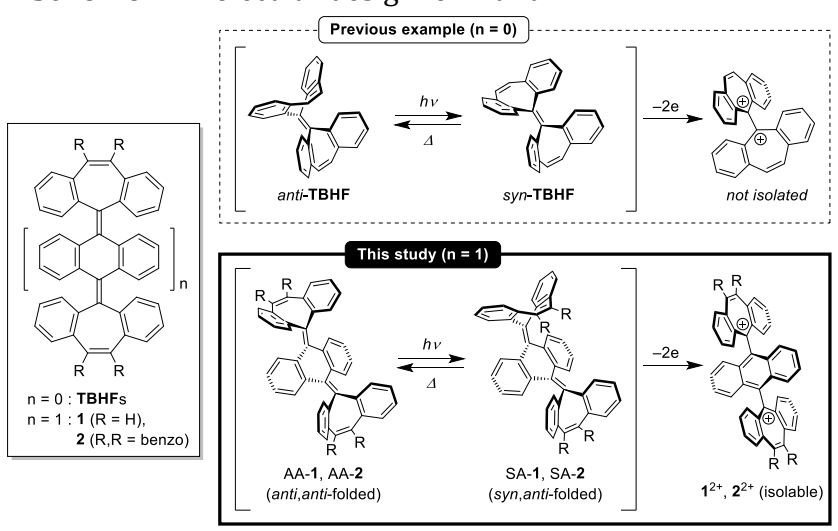




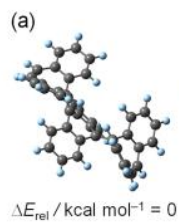

(b)

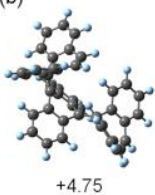

(f)
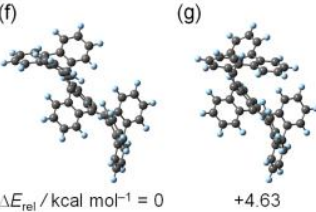

(c)

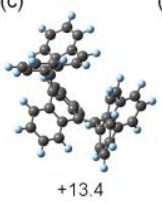

(h)

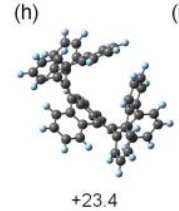

(d)

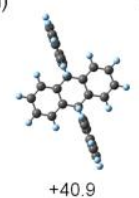

(e)
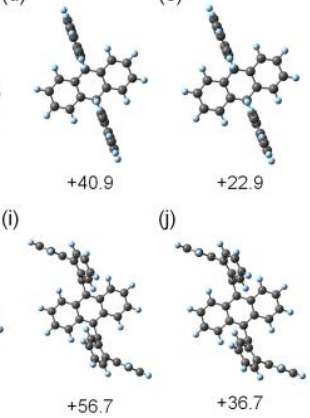

Figure 1. Optimized structures of (a) AA-1, (b) SA-1, (c) SS-1, (d) T-1, (e) TD-1", (f) AA-2, (g) SA-2, (h) SS-2, (i) T-2, and (j) TD-2" based on DFT calculations at the (U)B3LYP/631G* level.

observed for the parent TBHF, however, it was only detected by NMR and UV-vis spectroscopy, ${ }^{42,43}$ and thus electrochromic behavior was not realized in those molecules. The spatial intimacy of two positive charges results in instability of the dicationic species, and thus insertion of a proper spacer (e.g., anthracene-9,10-diyl) can solve the problem as exemplified by our recent studies on the dication of tetraarylanthraquinodimethanes (Ar 4 AQDs). ${ }^{44,45}$

Herein, we designed hydrocarbon-based OCE 1, in which an AQD skeleton is incorporated into two dibenzocycloheptatriene units (Scheme 1). This molecule would exhibit two or more patterns of structural changes upon photoirradiation and heating. The resulting configurational isomer would have different electron-donating properties due to the difference in deformation of the conjugation, and thus, the applied electric potential needed to give the corresponding cationic species would be different. To observe the enhanced switching properties, 2 with two tribenzocycloheptatriene units, and greater steric hindrance, was also designed. We expect that these OCEs 1 and $\mathbf{2}$ show quantitative photo- and thermal interconversion among the isolable configurational isomers with different oxidation potentials, which can selectively undergo redox interconversion with $\mathbf{1}^{2+}$ and $\mathbf{2}^{2+}$.

Previously, redox-active OCEs with several conformers have been developed based on bistricyclic aromatic enes (BAEs) such as bianthrones ${ }^{30,31}$ and bisthiaxanthylidenes ${ }^{33,34}$ by Evans and Feringa. These BAEs have syn/antifolded and twisted isomers, where conformers have different redox potentials. Although the redox potential can be switched by heat or light, higher-energy conformers are kinetically unstable and easily converted to the most stable isomer under ambient conditions, so that activation/deactivation by light/heat could not be applied for switching.

As shown above, few examples in which redox-active OCEs adopt two or more configurations in the neutral state have been reported, and this paper reports the first description of what oxidative properties among isomers were completely switched upon photoirradiation and heating, thus demonstrating light/heat-induced activation/deactivation of redox reactions based on isolable conformers. (a)

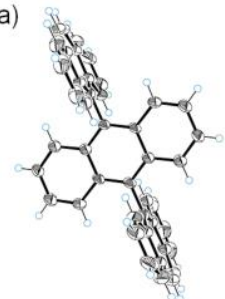

(d)

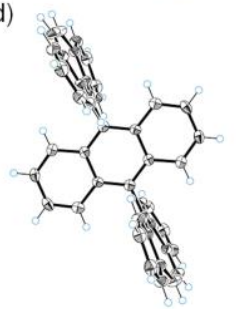

(b)

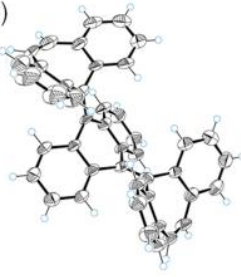

(e)

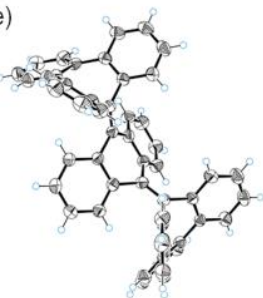

(c)

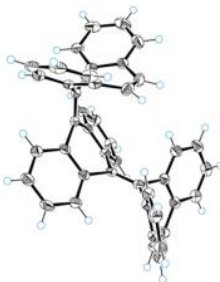

(f)

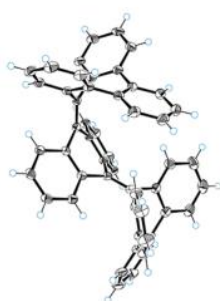

Figure 2. ORTEP drawings of (a) $\mathbf{1}^{2+}\left(\mathrm{BF}_{4}^{-}\right)_{2}$, (b) AA-1, (c) SA-1, (d) $\mathbf{1}^{2+}\left(\mathrm{SbCl}_{6}\right)_{2}$, (e) AA-2, and (f) SA-2. The counterions and solvent molecules are omitted for clarity. Thermal ellipsoids are shown at the $50 \%$ probability level.

\section{RESULTS AND DISCUSSION}

\section{DFT Calculations and Preparation}

Based on the above molecular design, a theoretical study was conducted for hydrocarbon $\mathbf{1}$. There are five possible structures [relative energy $E_{\mathrm{rel}} / \mathrm{kcal} \mathrm{mol}^{-1}$ : 0 for anti,anti-1 (AA-1), +4.75 for syn, anti-1 (SA-1), +13.4 for syn,syn-1 (SS1), +40.9 for twisted $\mathbf{1}(\mathrm{T}-\mathbf{1})$, and +22.9 for triplet diradical 1" (TD-1")] in the neutral state optimized by density functional theory (DFT) calculations ${ }^{46}$ at the (U)B3LYP/6-31G* level (Figures 1a-e). Similar results were obtained for 2 $\left[E_{\text {rel }} / \mathrm{kcal} \mathrm{mol}^{-1}: 0\right.$ for AA-2, +4.63 for SA-2, +23.4 for SS-2, +56.7 for T-2, and +36.7 for TD-2*], and the data are summarized in Figures $1 \mathrm{f}-\mathrm{j}$. By considering the relative energies, we could find two or more isomers, and started synthetic studies.

As shown in Scheme 2, diol 3 was prepared by lithiation of 9,10-dibromoanthracene followed by the addition of dibenzosuberenone. Upon treatment of $\mathbf{3}$ with acidic conditions, dication salt $\mathbf{1}^{2+}\left(\mathrm{BF}_{4}^{-}\right)_{2}$ was isolated in $96 \%$ yield as a red powder, the structure of which was identified by X-ray analysis (Figure 2a). The dication $\mathbf{1}^{2+}$ adopts an almost

Scheme 2. Preparation scheme for $\mathbf{1}$ and 2.
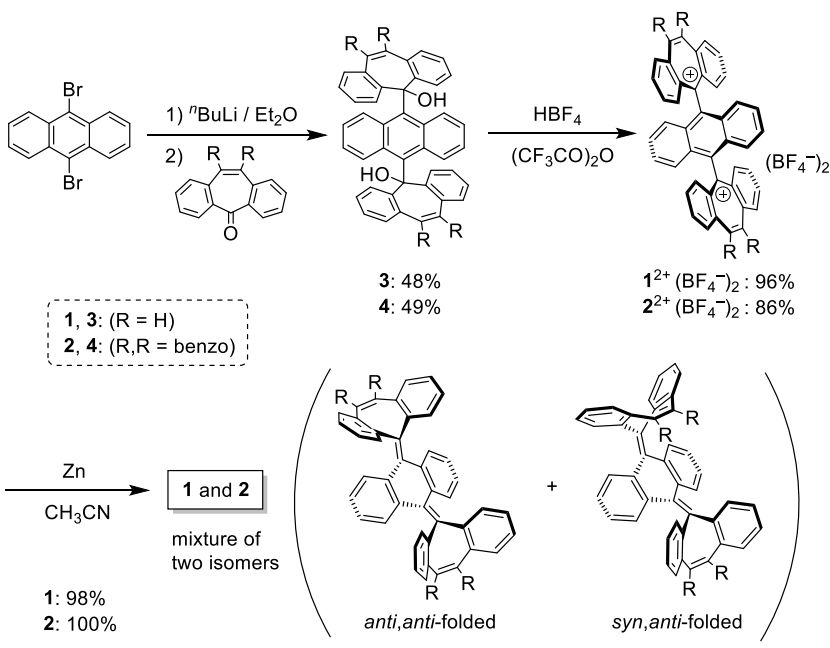

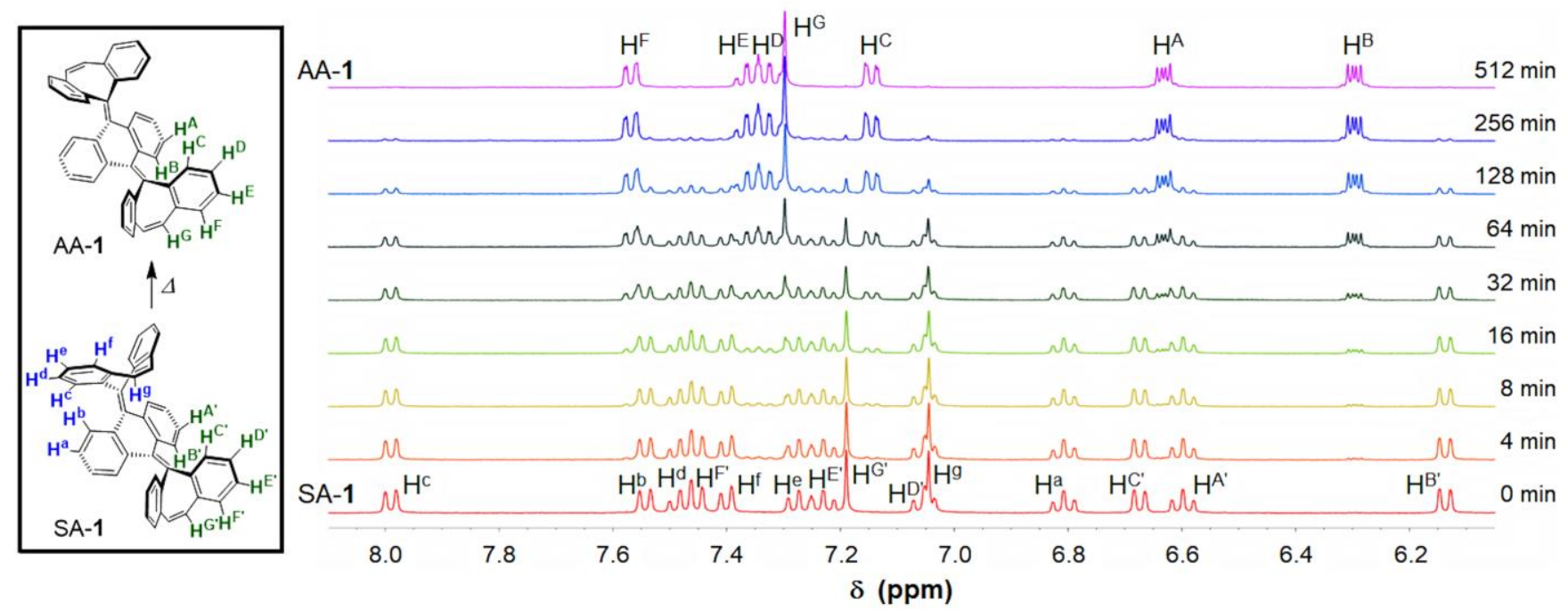

Figure 3. A change in ${ }^{1} \mathrm{H}$ NMR spectrum of SA-1 in DMSO- $d_{6}$ at $170{ }^{\circ} \mathrm{C}$.

orthogonally twisted structure and the dihedral angle between dibenzotropylium and anthracene units was determined to be $84.7^{\circ}$, which is in good agreement with the simulated value of $90.0^{\circ}$ (Figure S12). The dication salt $\mathbf{1}^{2+}\left(\mathrm{BF}_{4}^{-}\right)_{2}$ exhibits strong absorption in the visible region $\left(\lambda_{\max }=567\right.$ $\mathrm{nm}, \log \varepsilon=3.96$ in $\mathrm{CH}_{3} \mathrm{CN}$ ), and the color persists for a long time in solution (Figure S13a). When dication $\mathbf{1}^{2+}$ was reduced with Zn powder, target compound 1 was quantitatively obtained as a mixture of two isomers assignable to AA-1 and SA-1 (1:1 ratio).

The observed product ratio of anti,anti- and syn,anti-isomers could be accounted for by the Hammond postulate: in exergonic reactions, a transition-state structure should be similar to that of the starting material with a potential energy that is close to that in the transition state. Because the potential energy of twisted diradical 1" would be much higher than those of AA-1 and SA-1, the difference between the energy levels for the transition states toward both folded isomers would be negligibly small, so that the two isomers were produced in almost the same ratio.

These two isomers can be partially separated by column chromatography on silica gel. The first and second eluted samples exhibit resonances corresponding to $C_{2 v}$-symmetric and $C_{s}$-symmetric species, respectively, characterized by ${ }^{1} \mathrm{H}$ NMR spectroscopy. X-ray analyses revealed that the former compound is AA-1 and the latter is SA-1 (Figures $2 b, c$ ). When tribenzosuberenone ${ }^{41}$ was used as the electrophile instead of dibenzosuberenone, AA-2 and SA-2 were obtained as a mixture. Their X-ray structures are shown in Figures 2e,f. In addition, the details of bond lengths for both isomers of $\mathbf{1}$ and $\mathbf{2}$ are summarized in Tables S1 and S2, showing that these molecules obviously adopt quinoidal forms not diradical species.

\section{Selective Thermal Isomerization from syn,anti- to anti,anti-isomers}

To investigate thermal interconversion, the mixture of isomers 1 was heated to reflux in dimethylsulfoxide (DMSO) for $1.5 \mathrm{~h}$, and pure AA-1 was obtained. This result indicates that AA-1 can be selectively obtained upon heating (oneway thermal isomerization to AA-1). To gain further insight into the thermal isomerization process for $\mathbf{1}$, isomerization from pure SA-1 to AA-1 was monitored by ${ }^{1} \mathrm{H}$ NMR spectroscopy. Upon heating at $170{ }^{\circ} \mathrm{C}$ in DMSO- $d_{6}$, thermal isomerization proceeded cleanly to give AA-1 (Figure 3), and the rate constant $k$ was determined to be $1.55 \times 10^{-4} \mathrm{~s}^{-1}$. In a similar manner, the rate constants of isomerization at 150 , 160,180 and $185{ }^{\circ} \mathrm{C}$ were determined and are summarized in Table S3. According to an Arrhenius plot using these values, the energy barrier for the thermal isomerization of SA1 was estimated to be $30.5 \mathrm{kcal} \mathrm{mol}^{-1}$, which is in accord with the fact that such isomerization does not occur at ambient temperature.

For SA-2, one-way thermal isomerization that was quantitatively, similar to that for AA-2 occurred when hexamethylphosphoramide (HMPA) was used as a higher-boiling solvent (Figure S14 and Table S3). The energy barrier for SA-2 was calculated to be $40.9 \mathrm{kcal} \mathrm{mol}^{-1}$, which is greater than that for SA-1 because increasing rigidity and steric hindrance around the cycloheptatriene ring makes ring-flipping more difficult.

\section{Selective Photoisomerization from anti,anti- to syn,anti-isomers}

Under photoirradiation conditions, anti,anti- and syn,anti-isomers of $\mathbf{1}$ were found to be interconvertible. To gain insight into the photostationary state, we photoirradiated a solution of pure SA-1 at $279 \mathrm{~nm}$, which is an isosbestic point. As a result, the isomer ratio converged to 19:81 of AA-1 and SA-1 in the photostationary state (Figure S15). Although the absolute quantum yield $(\Phi)$ was not determined, $\Phi_{\mathrm{AA}-1 \rightarrow \mathrm{SA}-1}$ is about 4 times as large as $\Phi_{\mathrm{SA}-1 \rightarrow \mathrm{AA}-1}$.

Furthermore, UV-vis spectra for AA-1 and SA-1 measured in $\mathrm{CH}_{2} \mathrm{Cl}_{2}$ (Figure 4a) show that the absorption edge wavelengths are 380 and $360 \mathrm{~nm}$, respectively. This means that selective photo-excitation of AA-1 would induce one-way photoisomerization into SA-1 when the solution of $\mathbf{1}$ is irradiated with UV light at a wavelength longer than $360 \mathrm{~nm}$. Actually, the behavior of photoisomerization for $\mathbf{1}$ was confirmed by UV-vis spectroscopy, in which the UV-vis spectrum exhibits a continuous change with several isosbestic points from AA-1 to SA-1 (Figure 4b). 
(a)

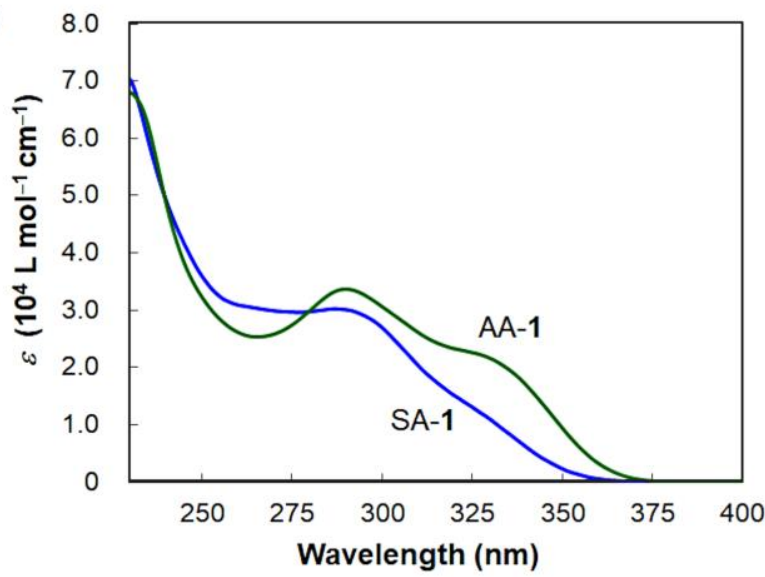

(b)

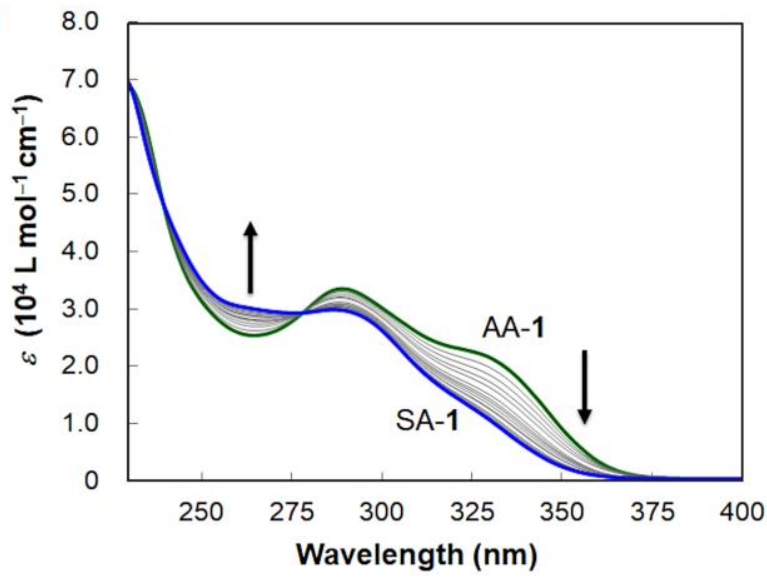

(c)

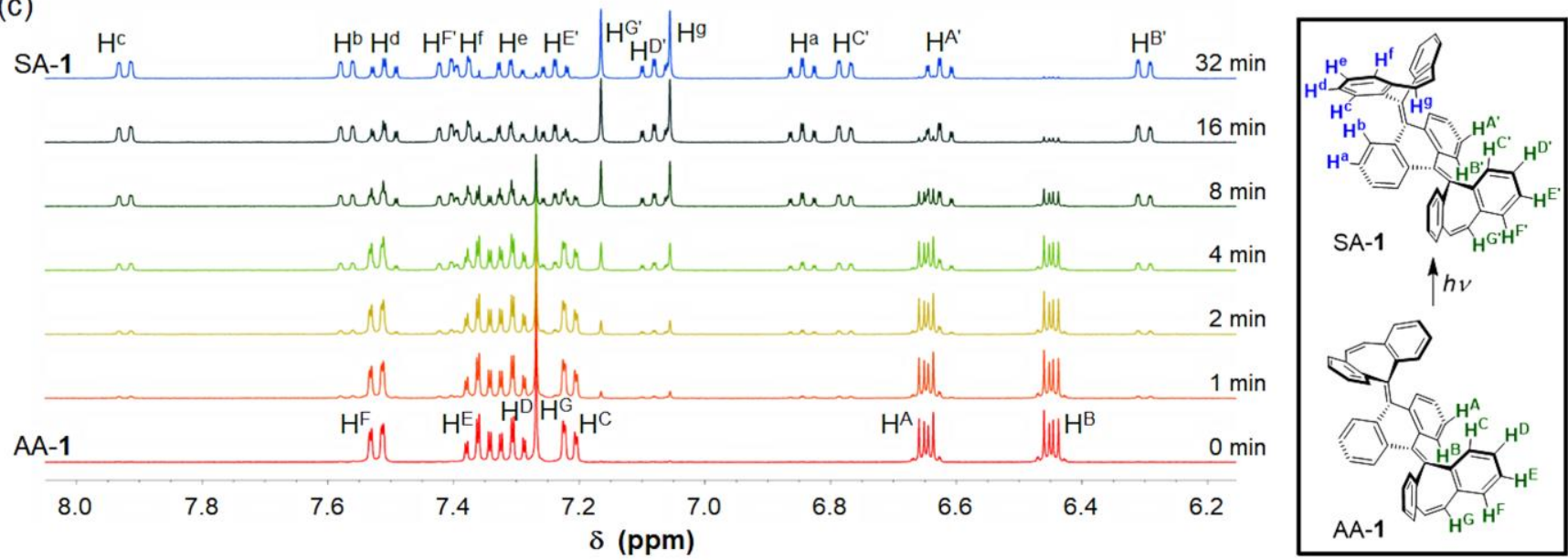

Figure 4. (a) UV-vis spectra of AA-1 (green) and SA-1 (blue) in $\mathrm{CH}_{2} \mathrm{Cl}_{2}$. (b) A change in UV-vis spectrum of AA-1 (green) to SA-1 (blue) in $\mathrm{CH}_{2} \mathrm{Cl}_{2}$ (0-20 min, every $2 \mathrm{~min} ; 20-40$ min, every $4 \mathrm{~min}$ ) and (c) a change in ${ }^{1} \mathrm{H}$ NMR spectrum of $\mathrm{AA}-1$ in $\mathrm{CD}_{2} \mathrm{Cl}_{2}$ upon photoirradiation at $365 \mathrm{~nm}$ [spectrofluorometer: $150 \mathrm{~W}$ Xe lamp, slit width (b) $5 \mathrm{~nm}$ and (c) $10 \mathrm{~nm}$ ].

To elucidate the details of photoisomerization, we investigated the isomerization of $\mathrm{AA}-1$ in $\mathrm{CD}_{2} \mathrm{Cl}_{2}$ by using NMR. Thus, SA-1 was obtained quantitatively, which was demonstrated by ${ }^{1} \mathrm{H}$ NMR spectroscopy as shown in Figure 4c. To confirm the absence of another isomer SS-1 in the photoreactions, the solution of SA-1 was irradiated with UV light at around $350 \mathrm{~nm}$, which is the absorption edge of SA-1. The UV-vis spectrum showed an increase only for the signals of AA-1, suggesting that incorporation of a higher-energy isomer was not involved.

Such photoisomerization can also be found in $\mathbf{2}$ because of the similarity of UV absorption properties (Figure S16). Based on these experimental results in combination with thermal reactivity, photo- and thermal isomerization proceed reversibly and quantitatively, which enables one-way isomerization between anti,anti- and syn,anti-isomers for both $\mathbf{1}$ and $\mathbf{2}$

\section{Redox Behavior}

The redox potentials of two isomers were measured by cyclic voltammetry in $\mathrm{CH}_{2} \mathrm{Cl}_{2}$ (Figure 5). As a result of the different configurations for $\mathbf{1}$, anti,anti- and syn,anti-isomers undergo electrochemical oxidation at different potentials $\left(E^{\circ x} / \mathrm{V}\right.$ vs. SCE: +1.66 for AA-1, +1.54 for SA-1) to produce the same twisted dication $\mathbf{1}^{2+}$. The two-electron process for oxidation was confirmed by using ferrocene as an external standard. Upon the electrochemical oxidation of SA-1 in $\mathrm{CH}_{2} \mathrm{Cl}_{2} /\left(\mathrm{CF}_{3}\right)_{2} \mathrm{CHOH}$ (9:1), clean conversion to $\mathbf{1}^{2+}$ (electrochromism) was observed with an isosbestic point (Figure 6), thus confirming the presence of a one-wave twoelectron oxidation process.

On the other hand, reduction of the dication $\mathbf{1}^{2+}$ occurred via a two-step one-electron process. Conversion of the

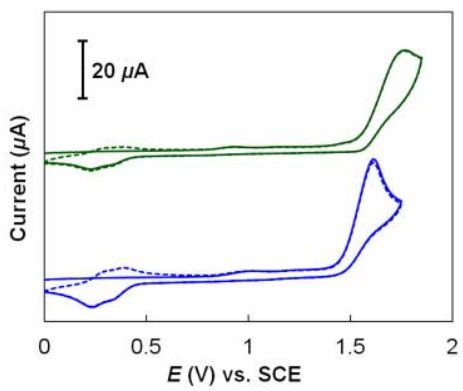

\begin{tabular}{ccc}
\hline & $E^{\text {ox }}(\mathrm{V})$ & $E^{\text {red }}(\mathrm{V})$ \\
\hline $\mathrm{AA}-1$ & +1.66 & - \\
\hline $\mathrm{SA}-1$ & +1.54 & - \\
\hline $1^{2+1} 1^{+}$ & $=E^{\text {red }}$ & +0.39 \\
\hline $1^{++11^{-}}$ & $=E^{\text {rod }}$ & +0.28 \\
\hline $\mathrm{AA}-2$ & $>+2.30$ & - \\
\hline $\mathrm{SA}-2$ & +1.73 & - \\
\hline $2^{2+}$ & - & +0.74 \\
\hline
\end{tabular}

Figure 5. Cyclic voltammograms of AA-1 (green) and SA-1 (blue) in $\mathrm{CH}_{2} \mathrm{Cl}_{2}$ containing $0.1 \mathrm{M} \mathrm{Bu}_{4} \mathrm{NBF}_{4}$ as a supporting electrolyte (scan rate $0.5 \mathrm{~V} \mathrm{~s}^{-1}$, Pt electrode). The second cycles are shown by dotted line. The redox potentials for these hydrocarbons are summarized in the table (scan rate $0.1 \mathrm{~V} \mathrm{~s}^{-1}$ ). The irreversible half-wave potentials were estimated from the anodic peak potentials $\left(E^{\mathrm{pa}}\right)$ as $E^{\mathrm{ox}}=E^{\mathrm{pa}}$ 0.03 or the cathodic peak potentials $\left(E^{\mathrm{pc}}\right)$ as $E^{\mathrm{red}}=E^{\mathrm{pc}}+0.03$. 


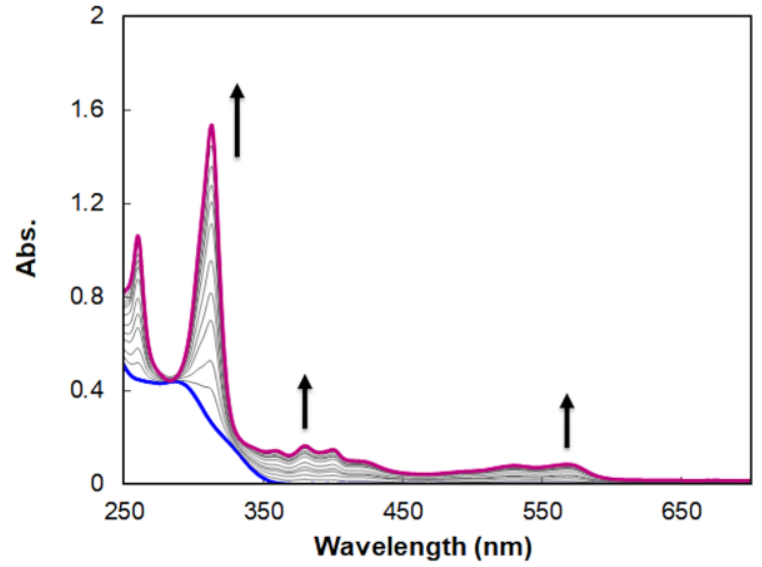

Figure 6. A change in the UV-vis spectrum of SA-1 (blue) to $\mathbf{1}^{2+}$ (violet) upon constant current electrochemical oxidation (80 $\mu \mathrm{A}$, every $2 \mathrm{~min})$ in $\mathrm{CH}_{2} \mathrm{Cl}_{2} /\left(\mathrm{CF}_{3}\right)_{2} \mathrm{CHOH}$ (9:1) containing $0.05 \mathrm{M} \mathrm{Bu}_{4} \mathrm{NBF}_{4}$ as a supporting electrolyte.

diradical into AA-1 and SA-1 proceeds rather slowly. In fact, two-step one-electron oxidation of the corresponding radical species was observed in the second cycle, indicating that the lifetime of twisted diradical 1" is longer than several seconds because of the large structural change between twisted diradical 1" and butterfly-shaped folded isomers $\mathbf{1}$.

Similar redox behavior was observed for SA-2 (Figure S17), and the oxidation peak appeared in the more anodic region $\left(E^{\mathrm{ox}}=+1.73 \mathrm{~V}\right)$ due to the lower aromatization energy of tribenzotropylium in $\mathbf{2}^{2+}$ compared to that of dibenzotropylium in $\mathbf{1}^{2+}$, which is accounted for by considering the addition of $\pi$-extended benzene rings to 1 . Notably, AA2 could not be oxidized even when the potential was scanned up to $+2.30 \mathrm{~V}$, which is a limit of $\mathrm{CH}_{2} \mathrm{Cl}_{2}$, and thus enhanced switching properties were observed in $\mathbf{2}$ when the potential difference was more than $0.5 \mathrm{~V}$.

To gain further insight into the different donating abilities of anti,anti- and syn,anti-isomers, theoretical calculations were conducted by the DFT method. The HOMO levels of anti,anti- and syn,anti-isomers are calculated to be -5.36 $\mathrm{eV}$ and $-5.40 \mathrm{eV}$ for 1 and $-5.46 \mathrm{eV}$ and $-5.46 \mathrm{eV}$ for 2 , respectively, at the B3LYP/6-31G* level. When the M06-2X method with the 6-31G* or cc-pVTZ basis set was used for calculations, no significant change was observed (Table S4). The nearly identical HOMO levels for the anti,anti- and syn,anti-isomers in both $\mathbf{1}$ and $\mathbf{2}$ seem incompatible with the experimental results regarding the different redox potentials. It is most probable that the discrepancy between the redox potentials and HOMO levels can be accounted for by the drastic structural change during two-electron transfer. Thus, syn,anti-isomers can be more easily oxidized than anti,anti-isomers due to large steric strain release after oneelectron oxidation, which may facilitate the subsequent electrochemical event in syn,anti-isomers.

\section{Redox Interconversion and Selective Oxidation}

As suggested by the voltammetric analyses, two configurational isomers AA-1 and SA-1 exhibited quite different behaviors upon redox interconversion with $\mathbf{1}^{2+}$. By considering the lower oxidation potential between two isomers, SA1 could be selectively oxidized by $\left(4-\mathrm{BrC}_{6} \mathrm{H}_{4}\right)_{3} \mathrm{~N}^{+} \mathrm{SbCl}_{6}{ }^{-}$ (Magic Blue), a representative one-electron oxidant. Upon treatment of SA-1 with two equivalents of Magic Blue, the dication $\mathbf{1}^{2+}\left(\mathrm{SbCl}_{6}{ }^{-}\right)_{2}$ (the structure of which is shown in Figure $2 \mathrm{~d}$ ) was obtained quantitatively while AA-1 did not react under the same conditions and was completely recovered (Scheme 3a). It is noteworthy that such selective oxidation of SA-1 was achieved when a 1:1 mixture of anti,antiand syn,anti-isomers was oxidized with two equivalents of Magic Blue (for details, see the Experimental section in the Supporting Information). This is a quite rare example of well-controlled redox switchable OCE because SA-1 obtained by photoirradiation can be selectively oxidized whereas AA-1 obtained by heat treatment remains intact. In the case of $\mathbf{2}$ with lower HOMO levels, Magic Blue is too weak, and thus a similar selective oxidation of SA-2 in the $1: 1$ mixture of two isomers was achieved by using $(2,4-$ $\left.\mathrm{Br}_{2} \mathrm{C}_{6} \mathrm{H}_{3}\right)_{3} \mathrm{~N}^{+} \cdot \mathrm{SbCl}_{6}{ }^{-}$as a stronger oxidant. ${ }^{47}$

\section{CONCLUSION}

We have designed and prepared redox-active OCEs $\mathbf{1}$ and 2 , for which both anti,anti- and syn,anti-folded isomers exist

Scheme 3. (a) Selective oxidation between anti,anti- and syn, anti-isomers. i) (4- $\left.\mathrm{BrC}_{6} \mathrm{H}_{4}\right)_{3} \mathrm{~N}^{+} \cdot \mathrm{SbCl}_{6}-\left(2.0\right.$ eq) in $\mathrm{CH}_{2} \mathrm{Cl}_{2}$ and ii) $(2,4-$ $\left.\mathrm{Br}_{2} \mathrm{C}_{6} \mathrm{H}_{3}\right)_{3} \mathrm{~N}^{+} \cdot \mathrm{SbCl}_{6}-(2.0 \mathrm{eq})$ in $\mathrm{CH}_{2} \mathrm{Cl}_{2}$. (b) The activation/deactivation process by light/heat and redox cycle for the hydrocarbons $\mathbf{1}(\mathrm{R}=\mathrm{H})$ and $2(\mathrm{R}, \mathrm{R}=$ benzo).

(a)

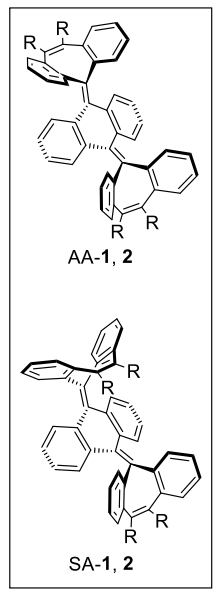

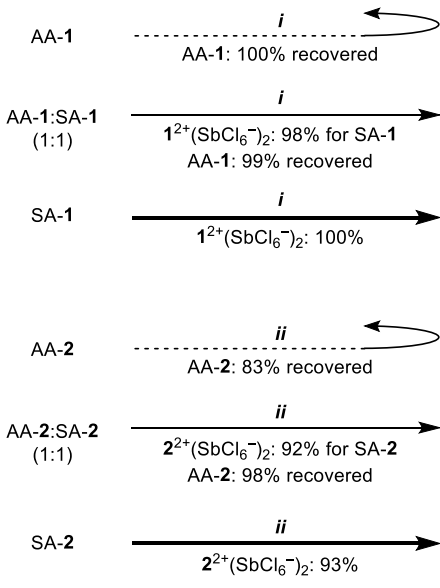
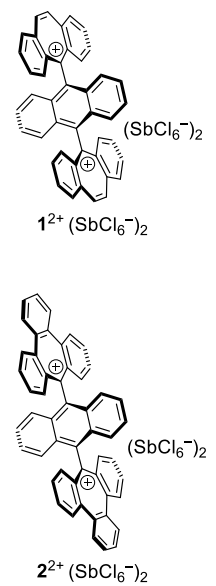

(b)

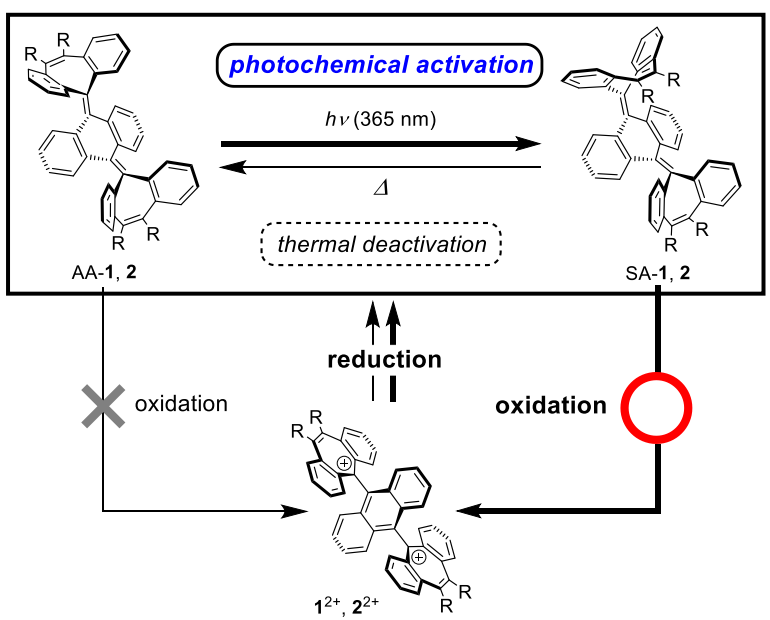


as stable entities due to rigid seven-membered rings as the key framework. These isomers do not interconvert at ambient temperature due to energy barriers greater than $30 \mathrm{kcal}$ $\mathrm{mol}^{-1}$. One-way thermal isomerization from syn,anti- to anti,anti-isomers and one-way photoisomerization from anti,anti- to syn,anti-isomers proceed quantitatively for both 1 and 2 . Furthermore, these hydrocarbons undergo two-electron oxidation to give twisted dications and dyrex behavior with a large separation of redox potentials, which gives favorable conditions for constructing electrochromic materials.

Furthermore, the much easier oxidation of SA-1 $(\Delta E=$ ca. $0.1 \mathrm{~V}$ ) than of AA-1 enables, in principle, activation/deactivation of the electrochromic properties of $\mathbf{1}$ by light/heat (Scheme 3b). Since photo- and thermal interconversion seldom changes the color, light and heat could be used only for the switching of electrochromism. As demonstrated by the larger difference in redox potentials $(\Delta E>0.5 \mathrm{~V})$ and the higher thermal activation energy in tribenzo derivative 2 , the activation/deactivation process by light/heat can be tuned by molecular design. Thus, the completely selective oxidation between anti,anti- and syn,anti-folded isomers, which can be switched by photo- and thermal isomerization, represents a new molecular concept for the design of smart functional devices.

\section{ASSOCIATED CONTENT}

\section{Supporting Information.}

The Supporting Information is available free of charge via the Internet at http://pubs.acs.org.

Synthetic details, characterization data, theoretical study, spectra, and crystallographic details (PDF)

$\mathrm{X}$-ray crystallographic data (CIF)

\section{AUTHOR INFORMATION}

\section{Corresponding Authors}

*E-mail: yishigaki@sci.hokudai.ac.jp

*E-mail: tak@sci.hokudai.ac.jp

\section{ORCID}

Yusuke Ishigaki: 0000-0001-7961-3595

Takanori Suzuki: 0000-0002-1230-2044

\section{Notes}

The authors declare no competing financial interest.

\section{ACKNOWLEDGMENT}

This work was supported by Grant-in-aid for Scientific Research on Innovative Areas: "Middle molecular strategy" (No. 2707) from MEXT and JSPS KAKENHI Grant Numbers (JP15H03790, JP18H04376, JP19K15528). Y.I. acknowledges the TOBEMAKI Scholarship Foundation and the Sasakawa Scientific Research Grant from The Japan Science Society. Y.H. is grateful for The Ministry of Education, Culture, Sports, Science and Technology through Program for Leading Graduate Schools (Hokkaido University "Ambitious Leader's Program"). This work was also supported by the "Five-star Alliance" in "NJRC Mater. \& Dev." MEXT. Mass spectra were measured by Dr. Eri Fukushi and Mr. Yusuke Takata at the GC-MS\&NMR Laboratory (Research Faculty of Agriculture, Hokkaido University).
This work is dedicated to Prof. Toshio Mukai on his 95th birthday.

\section{REFERENCES}

(1) Wu, Y.-T.; Siegel, J. S. Aromatic Molecular-Bowl Hydrocarbons: Synthetic Derivatives, Their Structures, and Physical Properties. Chem. Rev. 2006, 106, 4843-4867.

(2) Sygula, A.; Rabideau, P. W. Synthesis and Chemistry of Polycyclic Aromatic Hydrocarbons with Curved Surfaces: Buckybowls. In Carbon-Rich Compounds; Wiley-VCH Verlag: Weinheim, FRG, 2006; pp 529-565.

(3) Feng, C.-N.; Kuo, M.-Y.; Wu, Y.-T. Synthesis, Structural Analysis, and Properties of [8]Circulenes. Angew. Chem. Int. Ed. 2013, 52, 7791-7794.

(4) Sakamoto, Y.; Suzuki, T. Tetrabenzo[8]Circulene: Aromatic Saddles from Negatively Curved Graphene. J. Am. Chem. Soc. 2013, 135, 14074-14077.

(5) Kashihara, H.; Asada, T.; Kamikawa, K. Synthesis of a Double Helicene by a Palladium-Catalyzed Cross-Coupling Reaction: Structure and Physical Properties. Chem. Eur. J. 2015, 21, 6523-6527.

(6) Fujikawa, T.; Segawa, Y.; Itami, K. Synthesis, Structures, and Properties of $\pi$-Extended Double Helicene: A Combination of Planar and Nonplanar $\pi$-Systems. J. Am. Chem. Soc. 2015, 137, 7763-7768.

(7) Gu, X.; Li, H.; Shan, B.; Liu, Z.; Miao, Q. Synthesis, Structure, and Properties of Tetrabenzo[7]Circulene. Org. Lett. 2017, 19, 2246-2249.

(8) Márquez, I. R.; Fuentes, N.; Cruz, C. M.; Puente-Muñoz, V.; Sotorrios, L.; Marcos, M. L.; Choquesillo-Lazarte, D.; Biel, B.; Crovetto, L.; Gómez-Bengoa, E.; González, M. T.; Martin, R.; Cuerva, J. M.; Campaña, A. G. Versatile Synthesis and Enlargement of Functionalized Distorted HeptagonContaining Nanographenes. Chem. Sci. 2017, 8, 1068-1074.

(9) Hosokawa, T.; Takahashi, Y.; Matsushima, T.; Watanabe, S.; Kikkawa, S.; Azumaya, I.; Tsurusaki, A.; Kamikawa, K. Synthesis, Structures, and Properties of Hexapole Helicenes: Assembling Six [5]Helicene Substructures into Highly Twisted Aromatic Systems. J. Am. Chem. Soc. 2017, 139, 18512-18521.

(10) Pun, S. H.; Chan, C. K.; Luo, J.; Liu, Z.; Miao, Q. A DipleiadieneEmbedded Aromatic Saddle Consisting of 86 Carbon Atoms. Angew. Chem. Int. Ed. 2018, 57, 1581-1586.

(11) Jiménez, V. G.; Tapia, R.; Medel, M. A.; Mariz, I. F. A.; Ribeiro, T.; Blanco, V.; Cuerva, J. M.; Maçôas, E.; Campaña, A. G. Aggregation-Induced Emission of [3]Cumulenes Functionalized with Heptagon-Containing Polyphenylenes. Chem. Commun. 2018, 54, 3359-3362.

(12) Clevenger, R. G.; Kumar, B.; Menuey, E. M.; Kilway, K. V. Synthesis and Structure of a Longitudinally Twisted Hexacene. Chem. Eur. J. 2018, 24, 3113-3116.

(13) Pun, S. H.; Wang, Y.; Chu, M.; Chan, C. K.; Li, Y.; Liu, Z.; Miao, Q. Synthesis, Structures, and Properties of Heptabenzo[7]Circulene and Octabenzo[8]Circulene. J. Am. Chem. Soc. 2019, 141, 9680-9686.

(14) Hu, Y.; Paternò, G. M.; Wang, X.-Y.; Wang, X.-C.; Guizzardi, M.; Chen, Q.; Schollmeyer, D.; Cao, X.-Y.; Cerullo, G.; Scotognella, F.; Müllen, K.; Narita, A. $\pi$-Extended Pyrene-Fused Double [7]Carbohelicene as a Chiral Polycyclic Aromatic Hydrocarbon. J. Am. Chem. Soc. 2019, 141, 12797-12803.

(15) Yamago, S.; Kayahara, E.; Iwamoto, T. OrganoplatinumMediated Synthesis of Cyclic $\pi$-Conjugated Molecules: Towards a New Era of Three-Dimensional Aromatic Compounds. Chem. Rec. 2014, 14, 84-100.

(16) Iwamoto, T.; Kayahara, E.; Yasuda, N.; Suzuki, T.; Yamago, S. Synthesis, Characterization, and Properties of [4]Cyclo-2,7Pyrenylene: Effects of Cyclic Structure on the Electronic Properties of Pyrene Oligomers. Angew. Chem. Int. Ed. 2014, $53,6430-6434$. 
(17) Darzi, E. R.; Jasti, R. The Dynamic, Size-Dependent Properties of [5]-[12]Cycloparaphenylenes. Chem. Soc. Rev. 2015, 44, 6401-6410.

(18) Li, P.; Zakharov, L. N.; Jasti, R. A Molecular Propeller with Three Nanohoop Blades: Synthesis, Characterization, and Solid-State Packing. Angew. Chem. Int. Ed. 2017, 56, 52375241.

(19) Sun, Z.; Suenaga, T.; Sarkar, P.; Sato, S.; Kotani, M.; Isobe, H. Stereoisomerism, Crystal Structures, and Dynamics of BeltShaped Cyclonaphthylenes. Proc. Nat. Acad. Sci. 2016, 113, 8109-8114.

(20) Hitosugi, S.; Sato, S.; Matsuno, T.; Koretsune, T.; Arita, R.; Isobe, H. Pentagon-Embedded Cycloarylenes with Cylindrical Shapes. Angew. Chem. Int. Ed. 2017, 56, 9106-9110.

(21) Segawa, Y.; Yagi, A.; Matsui, K.; Itami, K. Design and Synthesis of Carbon Nanotube Segments. Angew. Chem. Int. Ed. 2016, 55, 5136-5158.

(22) Povie, G.; Segawa, Y.; Nishihara, T.; Miyauchi, Y.; Itami, K. Synthesis of a Carbon Nanobelt. Science 2017, 356, 172-175.

(23) Povie, G.; Segawa, Y.; Nishihara, T.; Miyauchi, Y.; Itami, K. Synthesis and Size-Dependent Properties of [12], [16], and [24]Carbon Nanobelts. J. Am. Chem. Soc. 2018, 140, 1005410059.

(24) Lu, X.; Gopalakrishna, T. Y.; Han, Y.; Ni, Y.; Zou, Y.; Wu, J. Bowl-Shaped Carbon Nanobelts Showing Size-Dependent Properties and Selective Encapsulation of $\mathrm{C}_{70}$. J. Am. Chem. Soc. 2019, 141, 5934-5941.

(25) Ishigaki, Y.; Shimajiri, T.; Takeda, T.; Katoono, R.; Suzuki, T. Longest C-C Single Bond among Neutral Hydrocarbons with a Bond Length beyond 1.8 Å. Chem 2018, 4, 795-806.

(26) Ishigaki, Y.; Hayashi, Y.; Sugawara, K.; Shimajiri, T.; Nojo, W.; Katoono, R.; Suzuki, T. 9,10-Dihydrophenanthrene with Two Spiro(Dibenzocycloheptatriene) Units: A Highly Strained Caged Hydrocarbon Exhibiting Reversible Electrochromic Behavior. Molecules 2017, 22, 1900.

(27) Jensen, F. R.; Smith, L. A. The Structure and Interconversion of Cycloheptatriene. J. Am. Chem. Soc. 1964, 86, 956-957.

(28) Hjelmencrantz, A.; Friberg, A.; Berg, U. Conformational Analysis of Some 5-Substituted $5 \mathrm{H}$ -

Dibenzo[a,d]Cycloheptenes. J. Chem. Soc. Perkin Trans. 2 2000, 1293-1300.

(29) Greb, L.; Lehn, J.-M. Light-Driven Molecular Motors: Imines as Four-Step or Two-Step Unidirectional Rotors. J. Am. Chem. Soc. 2014, 136, 13114-13117.

(30) Olsen, B. A.; Evans, D. H. Electron-Transfer Reactions and Conformational Changes Associated with the Reduction of Bianthrone. J. Am. Chem. Soc. 1981, 103, 839-843.

(31) Evans, D. H.; Busch, R. W. Electron-Transfer Reactions and Associated Conformational Changes. Extended Redox Series for Some Bianthrones, Lucigenin, and Dixanthylene. J. Am. Chem. Soc. 1982, 104, 5057-5062.

(32) Suzuki, T.; Fukushima, T.; Miyashi, T.; Tsuji, T. Isolation and $\mathrm{X}$-Ray Structural Determination of Both Folded and Twisted Conformers of Bis $\{4 H, 8 H-4$-(Dicyanomethylene)-Benzo[1,2$\left.c: 4,5-C^{\prime}\right]$ Bis $[1,2,5]$ Thiadiazol-8-Ylidene $\}$, an Overcrowded Ethylene with High Electron Affinity. Angew. Chem. Int. Ed. English 1997, 36, 2495-2497.

(33) Browne, W. R.; Pollard, M. M.; de Lange, B.; Meetsma, A.; Feringa, B. L. Reversible Three-State Switching of Luminescence: A New Twist to Electro- and Photochromic Behavior. J. Am. Chem. Soc. 2006, 128, 12412-12413.

(34) Ivashenko, O.; Logtenberg, H.; Areephong, J.; Coleman, A. C.; Wesenhagen, P. V.; Geertsema, E. M.; Heureux, N.; Feringa, B. L.; Rudolf, P.; Browne, W. R. Remarkable Stability of High Energy Conformers in Self-Assembled Monolayers of a Bistable Electro- and Photoswitchable Overcrowded Alkene. J. Phys. Chem. C 2011, 115, 22965-22975.

(35) Matsuo, Y.; Wang, Y.; Ueno, H.; Nakagawa, T.; Okada, H. Mechanochromism, Twisted/Folded Structure Determination, and Derivatization of ( $N$-Phenylfluorenylidene)Acridane. Angew. Chem. Int. Ed. 2019, 58, 8762-8767.

(36) Bergmann, E. D.; Ginsburg, D.; Hirshberg, Y.; Mayor, M.; Pullman, A.; Pullman, B. Fulvenes and Thermochromic Ethylenes. XIII. The Heptafulvenes and Their Tetrabenzo Derivatives. Bull. Soc. Chim. Fr. 1951, 18, 697-701.

(37) Schönberg, A.; Sodtke, U.; Praefcke, K. Über Stereoisomere Und Photochemie Des $2.3 ; 6.7 ; 2^{\prime} .3^{\prime} ; 6^{\prime} .7^{\prime}$-TetrabenzoHeptafulvalens. Tetrahedron Lett. 1968, 9, 3253-3256.

(38) Schönberg, A.; Sodtke, U.; Praefcke, K. Darstellung, Reaktionen Und Stereochemie Der $2.3 ; 6.7 ; 2^{\prime} .3^{\prime} ; 6^{\prime} .7^{\prime}$ Tetrabenzo-Heptafulvalene. Chem. Ber. 1969, 102, 14531467.

(39) Dichmann, K. S.; Nyburg, S. C.; Pickard, F. H.; Potworowski, J. a. The Crystal and Molecular Structures of Two Stereoisomers of $\Delta^{5,5^{\prime}}$-Bi-5H-Dibenzo[ $[a, d]$ Cycloheptene $\left(2,3 ; 6,7 ; 2^{\prime} 3^{\prime} ; 6^{\prime}, 7^{\prime}\right.$ Tetrabenzoheptafulvalene). Acta Crystallogr. Sect. B Struct. Crystallogr. Cryst. Chem. 1974, 30, 27-36.

(40) Agranat, I.; Suissa, M. R. Syn, Anti Isomerization of 5,5'-Bis$5 H$-Dibenzo[ $a, d]$ Cyclohepten-5-Ylidene. Struct. Chem. 1993, 4, 59-66.

(41) Luo, J.; Song, K.; Gu, F. long; Miao, Q. Switching of Non-Helical Overcrowded Tetrabenzoheptafulvalene Derivatives. Chem. Sci. 2011, 2, 2029-2034.

(42) Malandra, J. L.; Mills, N. S.; Kadlecek, D. E.; Lowery, J. A. Dications of Tetrabenzofulvalenes. Paratropicity and .Sigma. Donation in Perpendicular Antiaromatic Systems. J. Am. Chem. Soc. 1994, 116, 11622-11623.

(43) Mills, N. S.; Levy, A.; Plummer, B. F. Antiaromaticity in Fluorenylidene Dications. Experimental and Theoretical Evidence for the Relationship between the HOMO/LUMO Gap and Antiaromaticity. J. Org. Chem. 2004, 69, 6623-6633.

(44) Sakano, Y.; Katoono, R.; Fujiwara, K.; Suzuki, T. Preparation, Redox Properties, and X-Ray Structures of Electrochromic 11,11,12,12-Tetraarylanthraquinodimethane and Its Bianthraquinodimethane Analogue: Drastic Geometrical Changes upon Interconversion with Dicationic Dyes. Chem. Lett. 2014, 43, 1143-1145.

(45) Ishigaki, Y.; Sugawara, K.; Yoshida, M.; Kato, M.; Suzuki, T. Two-Way Chromic Systems Based on Tetraarylanthraquinodimethanes: Electrochromism in Solution and Mechanofluorochromism in a Solid State. Bull. Chem. Soc. Jpn. 2019, 92, 1211-1217.

(46) Gaussian 16, Revision A.03; Frisch, M. J.; Trucks, G. W.; Schlegel, H. B.; Scuseria, G. E.; Robb, M. A.; Cheeseman, J. R.; Scalmani, G.; Barone, V.; Petersson, G. A.; Nakatsuji, H.; Li, X.; Caricato, M.; Marenich, A. V.; Bloino, J.; Janesko, B. G.; Gomperts, R.; Mennucci, B.; Hratchian, H. P.; Ortiz, J. V.; Izmaylov, A. F.; Sonnenberg, J. L.; Williams-Young, D.; Ding, F.; Lipparini, F.; Egidi, F.; Goings, J.; Peng, B.; Petrone, A.; Henderson, T.; Ranasinghe, D.; Zakrzewski, V. G.; Gao, J.; Rega, N.; Zheng, G.; Liang, W.; Hada, M.; Ehara, M.; Toyota, K.; Fukuda, R.; Hasegawa, J.; Ishida, M.; Nakajima, T.; Honda, Y.; Kitao, O.; Nakai, H.; Vreven, T.; Throssell, K.; Montgomery, J. A., Jr.; Peralta, J. E.; Ogliaro, F.; Bearpark, M. J.; Heyd, J. J.; Brothers, E. N.; Kudin, K. N.; Staroverov, V. N.; Keith, T. A.; Kobayashi, R.; Normand, J.; Raghavachari, K.; Rendell, A. P.; Burant, J. C.; Iyengar, S. S.; Tomasi, J.; Cossi, M.; Millam, J. M.; Klene, M.; Adamo, C.; Cammi, R.; Ochterski, J. W.; Martin, R. L.; Morokuma, K.; Farkas, O.; Foresman, J. B.; Fox, D. J. Gaussian, Inc., Wallingford CT, 2016.

(47) Aranzaes, J. R.; Daniel, M.-C.; Astruc, D. Metallocenes as References for the Determination of Redox Potentials by Cyclic Voltammetry - Permethylated Iron and Cobalt Sandwich Complexes, Inhibition by Polyamine Dendrimers, and the Role of Hydroxy-Containing Ferrocenes. Can. J. Chem. 2006, 84, 288-299. 


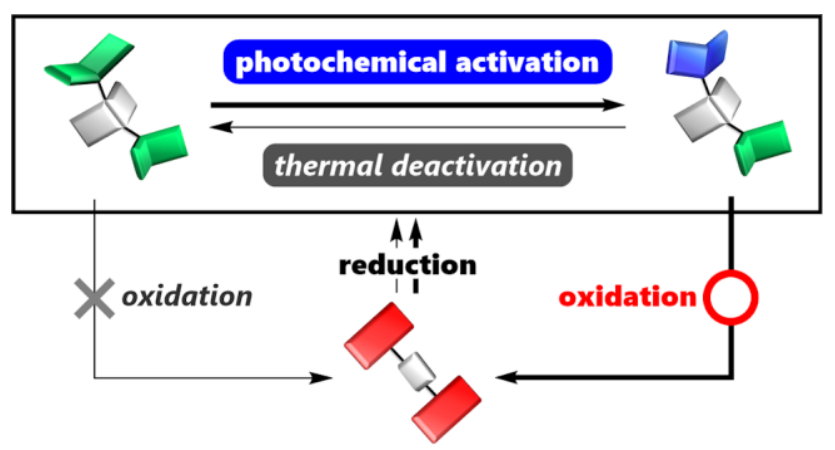

